\title{
Condon' ${ }^{\prime} 13$
}

\section{Th 1610}

Identification and Evaluation of CCS Sweet Spots in the West Netherlands Basin

K.A. van Toorenenburg* (Delft University of Technology), M.E. Donselaar (Delft University of Technology), V.P. Vandewijer (TNO), M.P. Pluymaekers (TNO), A.A. van de Weerd (PanTerra Geoconsultants B.V.), R.M. Groenenberg (Delft University of Technology) \& J.S. Flores Colmenares (Delft University of Technology)

\section{SUMMARY}

Carbon Capture and Sequestration (CCS) is expected to become a serious CO2-emission reduction technology in the Netherlands, for example in the mature West Netherlands Basin (WNB). This study aims to identify and evaluate potential CO2-storage reservoirs based on geological boundary conditions. These criteria are applied to a basin-scale structural model of the WNB in combination with a literature review on lithology and petrophysical parameters of the targeted Triassic and Upper Jurassic to Lower Cretaceous intervals. Selected 'sweet spots' are evaluated through the construction of high-resolution 3D static reservoir models. These serve as the basis for estimations of CO2-storage capacity, dynamic flow modelling and overburden studies.

The results of this study are not only important for the selection of locations for future CCS projects, but they also serve to assess the proposed workflow, showing that reservoir structure, facies architecture and petrophysical properties play a major role in calculating storage potential. Furthermore, the conventional approach to calculating CO2-storage capacity from average petrophysical values is found to significantly overestimate injectable volumes when compared to the results of this study. This emphasises the need for an accurate facies distribution model in estimating the $\mathrm{CO} 2$-storage potential. 


\section{Introduction}

Carbon capture and sequestration (CCS) is expected to become a serious $\mathrm{CO}_{2}$-emission reduction technology in the Netherlands. The industry- and government-supported national research programme CATO-2 is tasked to investigate the opportunities and feasibility of CCS projects, both onshore and offshore in the Dutch territory. To this end, demand-driven research is performed with focus on facilitating and enabling integrated development along the entire CCS chain.

An example of geological $\mathrm{CO}_{2}$-storage opportunities are the deep aquifers and (soon-to-be) depleted gas reservoirs in the West Netherlands Basin (WNB), conveniently situated near $\mathrm{CO}_{2}$-emitting sources in the Rotterdam industrial area and a future $>1,000 \mathrm{MW}$ coal-fired power station. The WNB is a mature area with a declining production of predominantly natural gas, but also oil. Production started in the 1950's and is mainly from Triassic and Upper Jurassic to Lower Cretaceous intervals (De Jager \& Geluk, 2007).

As part of the CATO-2 research, an identification and evaluation study of sweet spots for $\mathrm{CO}_{2}$-storage in the WNB was performed to assess the opportunities for future CCS development. In this paper, the results of this study and their implications for assessing the storage potential are briefly elucidated.

\section{Basin geological setting}

The regional geology of the WNB has been extensively described in earlier publications (e.g. RaceroBaena \& Drake, 1996, and Wong et al. 2007); therefore only a summary will be presented here. The WNB is a basin (150 by $60 \mathrm{~km}$; Fig. 1) with a complex geological history, involving phases of rifting, regional peneplanisation and basin inversion, causing several angular unconformities (Fig. 2).

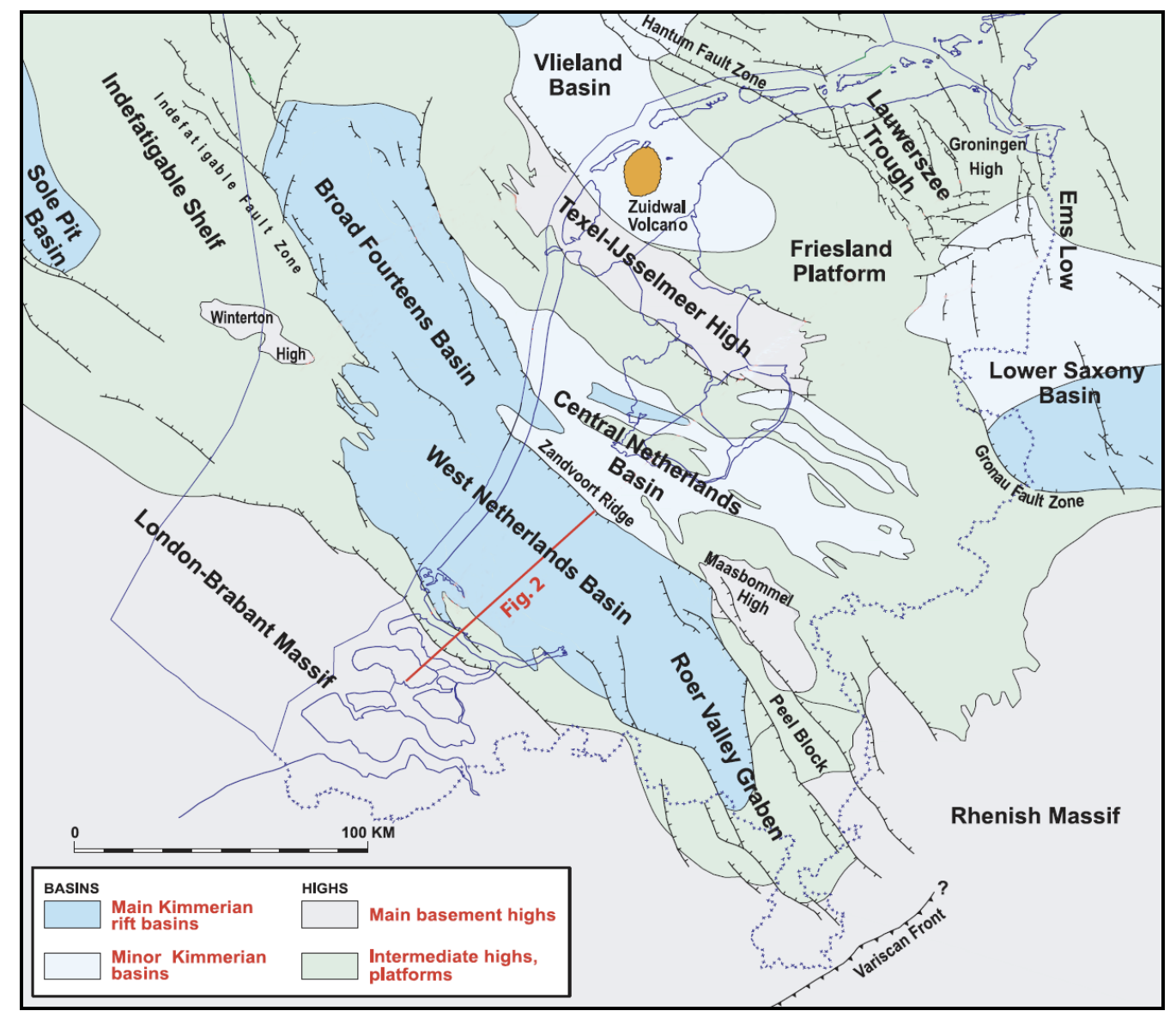

Figure 1 Structural map of the Dutch subsurface showing Jurassic and Early Cretaceous basins, highs and platforms, including the West Netherlands Basin (modified from De Jager, 2007). 


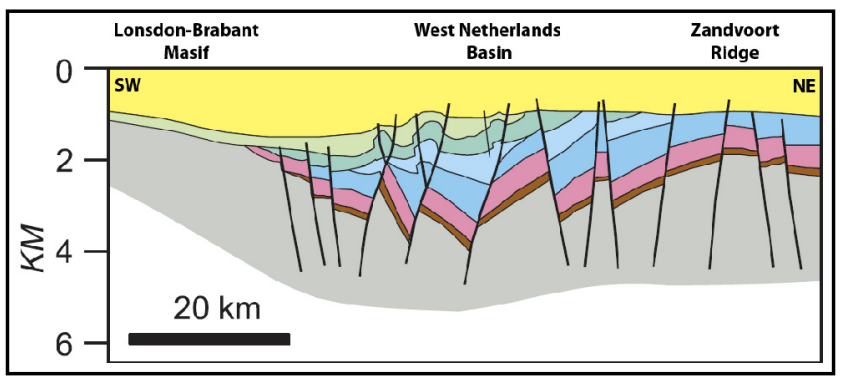

Figure 2 Regional cross-section of the West Netherlands Basin (Fig. 1); colour legend in Fig. 3 (modified from De Jager, 2007).

A thin package of Lower Permian Rotliegend clastics were laid down on the Variscan unconformity, followed by Upper Permian Zechstein clastics and carbonates. Unlike in the rest of the Northwest European Gas Province, salt deposits are absent. Due to their proximity to the London-Brabant Massif in the south, Triassic Buntsandstein clastics adjacent to this structural high are thicker and sandier when compared to parts of the basin further to the north. Lower and Middle Jurassic rocks are mainly marine shales, including the prolific Posidonia Shale oil source rock (Fig. 3).

During the Late Jurassic and Early Cretaceous, the WNB was subjected to phases of intense rifting. Initially, only terrestrial clastics of the Delfland Subgroup and Vlieland Sandstone were deposited (Fig. 3), but subsequent sediments were laid down in marine environments.

In the Late Cretaceous, a thick package of Chalk was deposited over the WNB (Fig. 3). Later on in the Cretaceous, structural inversion of the basin started and large sections of older rocks were eroded below a Paleogene unconformity, particularly in the centre and the eastern part of the basin (Fig. 2). During most of the Cenozoic, slow subsidence and clastic deposition took place and faults became inactive.

\section{Basin model and sweet spot identification}

The identification of sweet spots for $\mathrm{CO}_{2}$ storage is based on pre-defined geological boundary conditions, including trap type, geological and petrophysical reservoir architecture, top-seal and fault-seal quality, $\mathrm{CO}_{2}$-storage capacity and reservoir depth, contributing to a costefficient reservoir (re)development at low environmental impact. These criteria are applied to a basin-scale structural model, in combination with a literature study on the lithology and petrophysical properties of the targeted stratigraphic intervals. The procedure used to do this is similar to that conducted by Bachu (2003) to assess and rank sedimentary basins for $\mathrm{CO}_{2}$ sequestration.

The data required for the construction of a basin-scale structural model of the WNB are gathered from a public database, along with a selection of models from earlier regional studies:

- A representative selection exploration and development wells, including deviation tables and well completion logs.

- All available 3D seismic data.

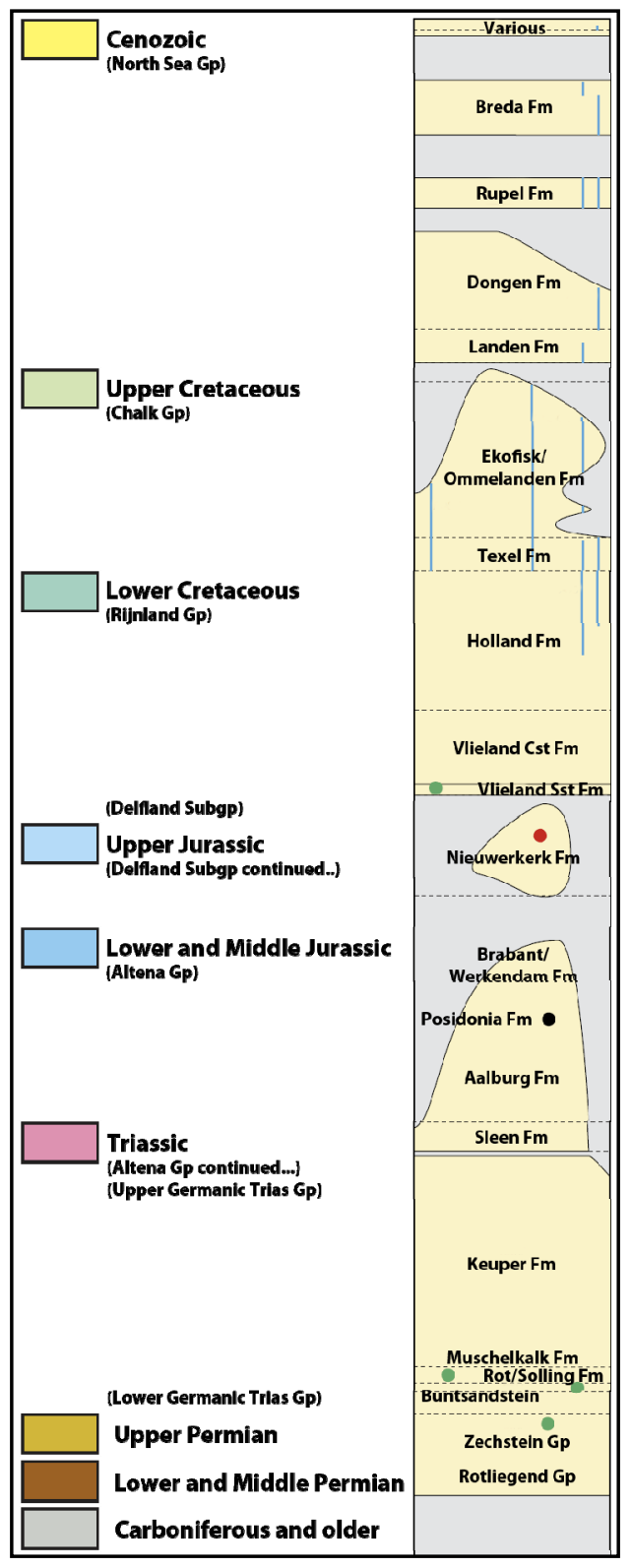

Figure 3 Tectono-stratigraphic chart of the West Netherlands Basin (modified from De Jager, 2007, and TNO, 2011).

- The VelMod-2 regional velocity model (Van Dalfsen et al. 2007).

- Regional mapping of major faults (Duin et al. 2006). 
Based on this dataset, a new tectono-stratigraphic framework is developed for the targeted Triassic and Upper Jurassic to Lower Cretaceous intervals to correlate the wells over the entire basin. Nine discernible horizons are interpreted from the available seismic data and correlated accordingly. These are then converted from time to depth using the velocity model and the corresponding well tops. Next, a fault model is created from the regional fault maps and all seismic and non-seismic horizons are reconstructed, honouring both well correlation and fault offset.

Thickness maps are derived from the structural model and combined with depth maps to identify geological structures suitable for $\mathrm{CO}_{2}$ storage. Lithology and petrophysical properties of the targeted intervals are then derived from literature. Based on this information, the suitability of each potential reservoir for $\mathrm{CO}_{2}$ sequestration is assessed.

\section{Sweet spot reservoir models and storage potential}

Based on the analysis and correlation of comprehensive subsurface datasets, provided by CATO-2 partners, high-resolution 3D static reservoir models are constructed for identified $\mathrm{CO}_{2}$-storage sweet spots. The higher density and completeness of the data allow for an accurate time-to-depth conversion, reconstruction of the structural architecture and modelling of the reservoir facies distribution. The models are populated with known petrophysical properties from the targeted intervals in the area and core tests (Fig. 4), in close correlation with the facies architecture.

The static models serve as the basis for $\mathrm{CO}_{2}$-storage capacity estimations, dynamic flow modelling and overburden studies. The various uncertainties in e.g. structural architecture, facies distribution and petrophysical properties are quantified through Monte Carlo simulation and their effects are evaluated. The results show that all of these factors have a significant influence on volumetric calculations.

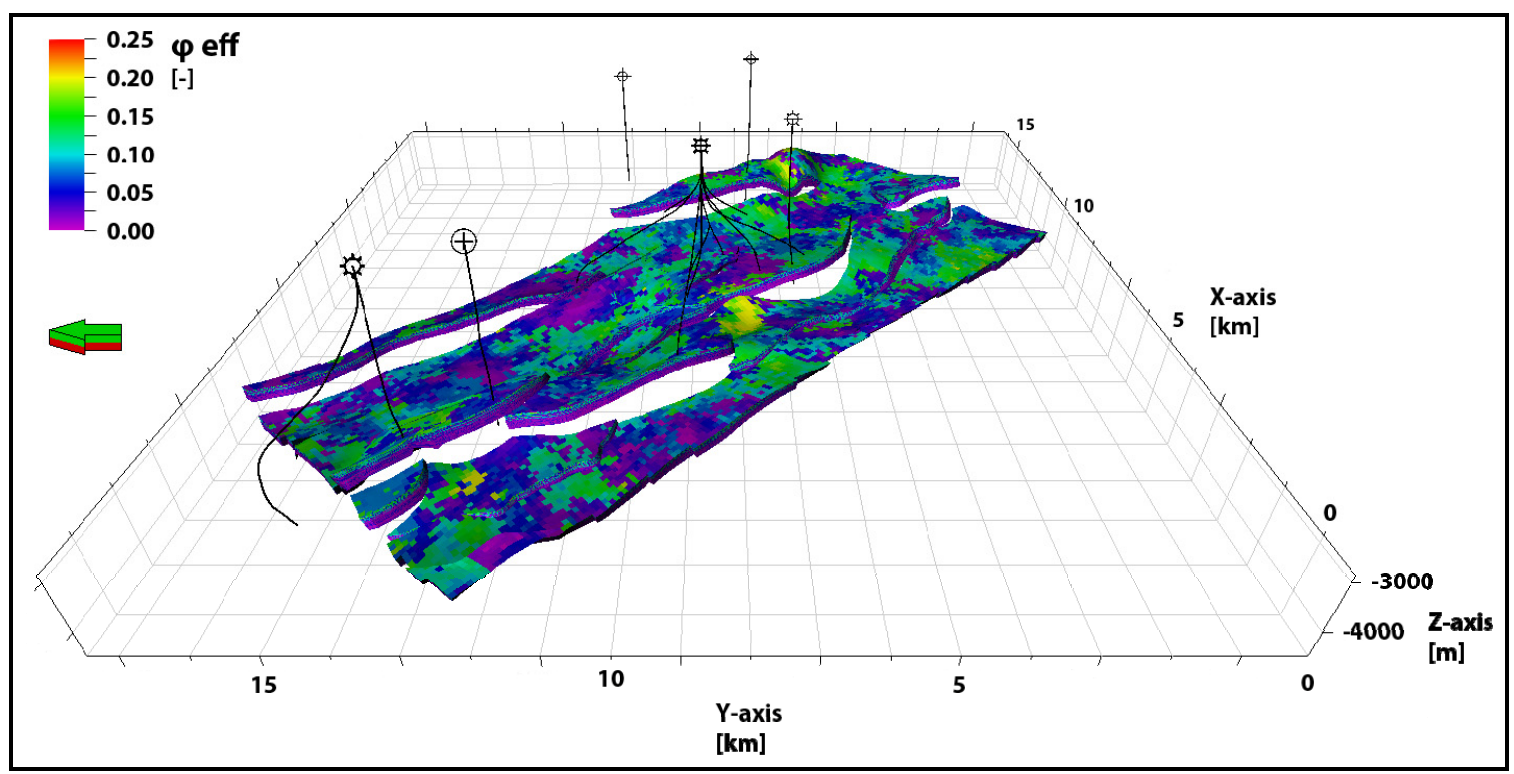

Figure 4 Modelled distribution of effective porosity $(\varphi$ eff) in the Lower Triassic P18 offshore gas field. Existing wells are shown in black; arrow indicates the North.

In case of the nearly-depleted P18 offshore gas field, a Buntsandstein (Lower Triassic) fluvial sandstone reservoir (Fig. 4), production data provide a solid baseline for validation of $\mathrm{CO}_{2}$-storage capacity estimations. Furthermore, the estimated $\mathrm{CO}_{2}$-storage capacity is compared with conventional estimates, which are based on anisotropic averaging of petrophysical properties without considering heterogeneity in the facies architecture. It is shown that, whilst the approach in this study still leaves a substantial uncertainty in the estimated storage capacity, the conventional estimates significantly 
overestimate injectable volumes and have an equal or greater uncertainty. Results from Vlieland Sandstone (Lower Cretaceous) shallow marine, coastal and fluvial reservoirs confirm this observation.

\section{Conclusions}

Through this study, important knowledge was obtained on the $\mathrm{CO}_{2}$-storage potential of Lower Triassic and Lower Cretaceous reservoirs in the WNB. Not only are these results important for selection of locations for future CCS projects, but they also serve to assess the proposed workflow, showing that reservoir structure, facies architecture and petrophysical properties play a major role in calculating storage potential and cause a considerable uncertainty. In addition, the conventional approach to estimating $\mathrm{CO}_{2}$-storage capacity from average petrophysical values is found to significantly overestimate injectable volumes when compared to the results of the approach in this study. This emphasises the need for an accurate facies distribution model and correlation of petrophysical properties in estimating the $\mathrm{CO}_{2}$-storage potential.

\section{Acknowledgements}

All partners of the CATO-2 programme are all gratefully acknowledged for their support, providing the subsurface datasets and funding needed to conduct this research. Annelies Bender is kindly thanked for her work on the WNB dataset and Gerhard Diephuis' valuable input on the geophysical workflow is greatly appreciated.

\section{References}

Bachu, S. [2003] Screening and ranking of sedimentary basins for sequestration of $\mathrm{CO}_{2}$ in geological media in response to climate change. Environmental Geology, 44, 277-289.

De Jager, J. [2007] Geological Development. In: Rondeel, H.E., Batjes, D.A.J. and Nieuwenhuijs, W.H. (Eds.) Geology of Gas and Oil under the Netherlands. Kluwer Academic Publishers, 5-26.

De Jager, J. and Geluk, M.C. [2007] Petroleum Geology. In: Wong, Th.E., Batjes, D.A.J. and De Jager, J. (Eds.) Geology of the Netherlands. Royal Netherlands Academy of Arts and Sciences, 241-264.

Duin, E.J.T., Doornenbal, J.C., Rijkers, R.H.B., Verbeek, J.W. and Wong, Th.E [2006] Subsurface structure of the Netherlands - results of recent onshore and offshore mapping. Netherlands Journal of Geosciences, 85(4), 245-276.

Racero-Baena, A. and Drake, J.D. [1996] Structural style and reservoir development in the West Netherlands oil province. In: Rondeel, H.E., Batjes, D.A.J. and Nieuwenhuijs, W.H. (eds.) Geology of Gas and Oil under the Netherlands. Kluwer Academic Publishers, 211-227.

TNO [2011] Tectono-stratigraphic charts of the Netherlands continental shelf. TNO Built Environment and Geosciences, 9.

Van Dalfsen, W., Van Gessel, S.F. and Doornenbal, J.C. [2007] Velmod-2. TNO report 2007-U-R1272C, TNO Built Environment and Geosciences.

Wong, Th.E., Batjes, D.A.J. and De Jager, J. [2007] Geology of the Netherlands. Royal Netherlands Academy of Arts and Sciences, 354. 